\title{
Myelofibrosis patients in Belgium: disease characteristics
}

\author{
T. Devos ${ }^{1}$, P. Zachée ${ }^{2}$, D. Bron ${ }^{3,4}$, L. Noens ${ }^{5}$, J. Van Droogenbroeck ${ }^{6}$, P. Mineur ${ }^{7}$, \\ Y. Beguin ${ }^{8}$, Z. Berneman 9 , F. S. Benghiat ${ }^{4}$, A. Kentos ${ }^{10}$, C. Chatelain ${ }^{11}$, \\ H. Demuynck ${ }^{12}$, J. Lemmens ${ }^{13}$, K. Van Eygen ${ }^{14}$, K. Theunissen ${ }^{15}$, \\ F. Trullemans ${ }^{16}$, P. Pierre ${ }^{17}$, W. Pluymers ${ }^{18}$, L. Knoops ${ }^{19}$
}

${ }^{1}$ Universitair Ziekenhuizen Leuven (UZ Leuven) en Katholieke Universiteit Leuven (KU Leuven), Leuven, Belgium, ${ }^{2}$ Ziekenhuis Netwerk Antwerpen Stuivenberg, Antwerpen, Belgium, ${ }^{3}$ Institut Jules Bordet, Bruxelles, Belgium, ${ }^{4}$ Hôpital Erasme, Brussels, Belgium, ${ }^{5}$ Universitair Ziekenhuis Gent, Gent, Belgium, ${ }^{6}$ Algemeen Ziekenhuis Sint-Jan, Brugge, Belgium, ${ }^{7}$ Grand Hôpital de Charleroi, Charleroi, Belgium, ${ }^{8}$ Centre Hospitalier Universitaire de Liège and Université de Liège, Liège, Belgium, ${ }^{9}$ Universitair Ziekenhuis Antwerpen, Edegem, Belgium, ${ }^{10} \mathrm{Centre}$ Hospitalier de Jolimont, Jolimont, Belgium, ${ }^{11}$ Cliniques Universitaires UCL de Mont-Godinne, Mont-Godinne, Belgium, ${ }^{12}$ Jan Yperman Ziekenhuis, leper, Belgium, ${ }^{13}$ Algemeen Ziekenhuis St-Augustinus, Wilrijk, Belgium, ${ }^{14}$ Algemeen Ziekenhuis Groeninge, Kortrijk, Belgium, ${ }^{15}$ Jessa Ziekenhuis, Hasselt, Belgium, ${ }^{16}$ Universitair Ziekenhuis Brussel, Brussel, Belgium, ${ }^{17}$ Clinique du Sud Luxembourg, Arlon, Belgium, ${ }^{18}$ Novartis Pharma, Vilvoorde, Belgium, ${ }^{19}$ Cliniques universitaires Saint-Luc and de Duve Institute, Université Catholique de Louvain, Brussels, Belgium

Objective: To date, only a small number of epidemiological studies on myelofibrosis have been performed. The current study aimed to characterize the myelofibrosis patient population in Belgium according to predefined disease parameters (diagnosis, risk categories, hemoglobin $<10 \mathrm{~g} / \mathrm{dl}$, spleen size, constitutional symptoms, platelet count, myeloblast count), with a view to obtaining a deeper understanding of the proportion of patients that may benefit from the novel myelofibrosis therapeutic strategies.

Methods: A survey was used to collect data on prevalence and disease parameters on all myelofibrosis patients seen at each of 18 participating hematologic centers in 2011. Aggregated data from all centers were used for analysis. Analyses were descriptive and quantitative.

Results: A total of 250 patients with myelofibrosis were captured; of these, 136 (54\%) were male and 153 $(61 \%)$ were over 65 years old. One hundred sixty-five $(66 \%)$ of myelofibrosis patients had primary myelofibrosis and 85 (34\%) had secondary myelofibrosis. One hundred ninety-three myelofibrosis patients $(77 \%)$ had a palpable spleen. About a third of patients (34\%) suffered from constitutional symptoms. Two hundred twenty-two (89\%) myelofibrosis patients had platelet count $\geq 50000 / \mu \mathrm{l}$ and 201 $(80 \%)$ had platelet count $\geq 100000 / \mu \mathrm{l}$. Of 250 patients, $85(34 \%)$ had a myeloblast count $\geq 1 \%$. Six $(2 \%)$ patients had undergone a splenectomy. Thirteen (5.2\%) patients had undergone radiotherapy for splenomegaly.

Conclusions: The results of this survey provide insight into the characteristics of the Belgian myelofibrosis population. They also suggest that a large proportion of these patients could stand to benefit from the therapies currently under development.

Keywords: Myelofibrosis, Prevalence, Characteristics, Management

\section{Introduction}

Primary myelofibrosis (MF), a rare type of myeloproliferative neoplasm (MPN), is a life-threatening hematologic malignancy. ${ }^{1}$ The disease can be a primary disorder or secondary to pre-existing polycythemia vera

Correspondence to: T. Devos, Hematology unit Universitair Ziekenhuizen Leuven, campus Gasthuisberg, Herestraat 49, 3000 Leuven, Belgium. Email: timothy.devos@uzleuven.be
(PPV-MF) and post-essential thrombocythemia (PET$\mathrm{MF})$. The disease is characterized by fibrosis of the bone marrow, enlargement of the spleen, progressive cytopenia, leukoerythroblastosis, extramedullary hematopoiesis, constitutional symptoms and functional symptoms as fatigue and itching that can severely diminish the patient's quality of life. ${ }^{2,3}$ The median overall survival for MF patients is 4 to 6 years from time of diagnosis. ${ }^{4,5}$ The major causes of death include 
progressive bone marrow failure, infections and transformation to acute leukemia. ${ }^{6}$

Published data on the incidence and prevalence of MF in Europe are limited. ${ }^{5,7-10}$ Estimates of the annual incidence of MF in Europe range between 0.3 and 0.6 cases per 100000 persons. ${ }^{5,7-9} \mathrm{MF}$ is most commonly diagnosed in patients over the age of $50,{ }^{7,9}$ and appears to be more frequent in men. ${ }^{5,7-9}$

Well-established factors predictive of a poor prognosis of MF include age ( $>65$ years), hemoglobin concentration $(<10 \mathrm{~g} / \mathrm{dl})$, leucocyte count $\left(>25 \times 10^{9} / \mathrm{l}\right)$, circulating blasts $(>1 \%)$ and the presence of one or more constitutional symptoms. Based on these factors, the international prognostic scoring system (IPSS) and the dynamic international prognostic scoring system (DIPSS) stratify MF patients into four groups: Low, Intermediate-1 (Int-1), Intermediate-2 (Int-2) and High risk. ${ }^{6,11}$ The risk scores are fundamental for risk-based management strategies in MF. The IPSS score is valid at diagnosis, while the DIPSS score can be used at any time during the disease. ${ }^{6,11}$ Subsequent to the above risk factors, the 'DIPSS plus' scoring system also takes into account erythrocyte transfusion dependence, thrombocytopenia $\left(<100 \times 10^{9} / 1\right)$ and unfavorable karyotype (including $+8,-7 / 7 \mathrm{q}-$, i(17q), inv(3), -5/5q-, 12p-, 11q23 rearrangements and complex karyotypes) as additional risk factors affecting survival. ${ }^{12}$

The only potentially curative approach in MF remains allogeneic hematopoietic stem cell transplantation (AHSCT). This approach tends to be limited to High- or Int-2-risk patients younger than 65 years of age due to a high incidence of morbidity and mortality associated with the procedure. ${ }^{13-16}$ Drug therapy in MF is adjusted to the predominant clinical symptom caused by anemia, splenomegaly (extramedullary hematopoiesis), or constitutional symptoms. Conventional drug therapy includes androgens, corticosteroids, erythropoiesis-stimulating agents (ESAs), danazol, thalidomide, lenalidomide and hydroxyurea. ${ }^{1,17,18}$ Although splenectomy can temporarily reduce spleen-related symptoms, the risks associated with surgery do not qualify it as a routine procedure. ${ }^{19}$ Splenic irradiation can be effective for palliating MF-associated splenomegaly, but the effects are transient. It can also increase morbidity and mortality of subsequent splenectomy. ${ }^{20}$

The discovery and characterization of the JAK2 V617F mutation in $2005^{21-24}$ in a majority of MF patients deepened the understanding of the pathogenesis of the disease. Subsequent advances in the development of therapies targeting the major symptoms of the disease (splenomegaly, burden of constitutional symptoms $)^{25-27}$ through inhibition of the JAK-STAT pathway offer new strategies in the management of MF patients. ${ }^{28-31}$

A number of such therapies are now entering clinical phase development. ${ }^{25-27}$ Only one of these to date, ruxolitinib (a JAK1-JAK2 inhibitor), has published data available on Phase III clinical testing. ${ }^{32}$ The clinical benefit of ruxolitinib versus placebo and best available therapy for MF was demonstrated in two prospective randomized Phase III clinical trials (COMFORT I\&II). ${ }^{33,34}$ The US Food and Drug Administration and European Medicines Agency granted marketing approval for ruxolitinib for the treatment of patients with MF in 2011 and 2012, respectively. ${ }^{34}$ The US Food and Drug Administration approved ruxolitinib for the treatment of intermediate and high risk MF while European Medicines Agency's approval is for treatment of disease-related splenomegaly or symptoms in adult patients with MF (irrespective of risk score).

The dose limiting toxicities of most JAK inhibitors tested so far include thrombocytopenia and anemia, ${ }^{31}$ potentially limiting the proportion of patients eligible for treatment. CYT387 (momelotinib) could be an exception, with recent Phase I/II studies suggesting an improvement in anemia including weaning from transfusion-dependence. ${ }^{36}$ This finding still needs to be confirmed in the ongoing phase III trial where patients are randomized to momelotinib versus ruxolitinib treatment (NCT01969838). The current study was designed to characterize the MF patient population in Belgium according to a number of disease parameters (diagnosis, risk categories, spleen size, constitutional symptoms, platelet count, myeloblast count), in view to obtain a better understanding of the proportion of patients that may benefit from the therapies currently under development. This 'real life' study involved the majority of the hematological centers of Belgium and captured all patients visiting one of the centers during 2011.

\section{Methods}

\section{Study design}

A scientific survey was designed for investigators to collect data on Belgian MF patients. The scientific survey was developed in collaboration with and endorsed by the MPN subcommittee of the Belgian Hematological Society. Data were collected for MF patients who had visited one of 18 major hematology centers in Belgium at least once during 2011 (see supplementary methods (Supplementary Material) for complete list of collaborating centers).

Microsoft Excel worksheets containing questions on patient details and specific disease-related parameters (gender, age, cell counts, spleen size, and presence of constitutional symptoms) and open questions related to management of their disease were sent to each participating center between January and March 2012. A full list of the parameters/questions included is provided in supplementary methods (Supplementary Material). 
Data were entered by the investigator directly into the Microsoft Excel worksheet. Patient data were based on medical records and were collected for the most recent visit at the center, whether this was at time of diagnosis or when already under treatment. For patients being treated with ruxolitinib, data were taken from the last visit prior to starting this treatment.

\section{Anonymization and analysis of data}

Once all requested information had been entered into the worksheet, pivot tables automatically consolidated the entered data per site, such that no individual patients could be identified beyond the site. Data were submitted for analysis in aggregated form only. Data from individual sites were then merged. Analyses were descriptive and quantitative. Data were analyzed according to disease sub-type (PMF, PPV-MF or PET-MF), IPSS and DIPSS risk categories and MF-specific characteristics (spleen size, the presence of constitutional symptoms, platelet count and myeloblast count). Both IPSS and DIPSS scoring systems assign points to five predictive risk factors: age ( $>65$ years), hemoglobin concentration $(<10 \mathrm{~g} / \mathrm{dl})$, leucocyte count $\left(>25 \times 10^{9} / \mathrm{l}\right)$, circulating blasts $(>1 \%)$ and the presence of one or more constitutional symptoms. ${ }^{6,11}$ Each risk factor counts for one point, except for anemia (hemoglobin concentration), for which DIPSS assigns two points. The sum of the points correlates with four risk groups: IPSS, Low (0 points), Int-1 (1 point), Int-2 (2 points) and High risk ( $>2$ points); DIPSS, Low $(0$ points), Int-1 (1-2 points), Int-2 (3-4 points) and High risk (5-6 points).

\section{Results}

\section{Demographic characteristics of patients}

A total of 250 patients with MF were captured in this survey; of these, $136(54 \%)$ were male and $153(61 \%)$ were over 65 years old. One hundred sixty-five $(66 \%)$ of MF patients had PMF and 85 (34\%) had PET-MF (57 patients, $23 \%$ ) or PPV-MF (28 patients, $11 \%$ ).

\section{The distribution of patients according to disease} characteristics

The distribution of the number of patients (\%) according to IPSS and DIPSS risk categories is shown in Table 1. Ninety per cent of patients were in the Int-1 to High risk categories for both the IPSS and DIPSS. The IPSS showed a roughly equal distribution between Int-1 (30\%), Int-2 (33\%) and High risk $(27 \%)$ categories for MF patients overall. For the DIPSS, about half of the patients $(49 \%)$ fell into the Int-1 risk category while a considerably smaller proportion of patients $(8 \%)$ were categorized as High risk; a similar proportion of patients to those in the IPSS were in the Int-2 risk category (34\%). As expected, the proportion of patients in the Intermediate and High risk categories was higher for patients older than 65 years than in other patients.

The majority of MF patients (193/250; 77\%) had a palpable spleen. In 81 patients (32\%), spleen size was $\geq 10 \mathrm{~cm}$ below the costal margin. The proportion of patients with a palpable spleen tended to increase with the risk category (up to 82 and $95 \%$ in the High risk category for IPSS and DIPSS, respectively) (Fig. 1), as did the proportion of patients with a spleen size $\geq 5 \mathrm{~cm}$ (and $\geq 10 \mathrm{~cm}$ ) (with the exception of Int-1 and Int-2 DIPSS categories, for which there was a similar spleen size distribution).

Most (222/250; 89\%) MF patients had a platelet count $\geq 50000 / \mu 1,201(90.5 \%)$ of whom had platelet count $\geq 100000 / \mu 1$. Similar proportions of patients with high platelet counts were observed when patients were grouped by age ( $\leq 65$ years or $>65$ years) (Table 2). The proportion of patients with a low platelet count increased with the risk category (Fig. 2), reflecting the development of thrombocytopenia as the disease progresses. There was no apparent association between spleen size and platelet count (Fig. 3).

About one-third of patients $(86 / 250 ; 34 \%)$ displayed at least one constitutional symptom impacting prognosis [night sweats, fever or weight loss $(>10 \%$ of initial body weight)]. Constitutional symptoms were reported for the majority of MF patients in the High risk category (46/67 [69\%] for IPSS; $15 / 19$ [79\%] for DIPSS). The spleen was palpable for a slightly higher proportion of patients with constitutional symptoms $(72 / 86[84 \%])$ than with no constitutional symptoms (121/164 [74\%]) (Fig. 4). Moreover, spleen size $\geq 5 \mathrm{~cm}$ below the costal margin seemed to be associated with the presence of constitutional symptoms ( $71 \%$ of patients with constitutional symptoms vs $42 \%$ of patients without constitutional symptoms).

Table 1 The distribution of the number of patients (\%) among risk categories according to IPSS and DIPSS risk categories and age classes

IPSS DIPSS

\begin{tabular}{|c|c|c|c|c|c|c|}
\hline \multirow[b]{2}{*}{ Risk category } & & \\
\hline & Overall $N=250$ & $\leq 65$ years $N=97$ & $>65$ years $N=153$ & Overall $N=250$ & $\leq 65$ years $N=97$ & $>65$ years $N=153$ \\
\hline High & 67 (27\%) & $12(12 \%)$ & $55(36 \%)$ & 19 (8\%) & - & $19(13 \%)$ \\
\hline Int-2 & $82(33 \%)$ & $26(27 \%)$ & $56(37 \%)$ & $84(34 \%)$ & 27 (28\%) & $57(37 \%)$ \\
\hline Int-1 & $76(30 \%)$ & 34 (35\%) & $42(27 \%)$ & $122(49 \%)$ & $45(46 \%)$ & 77 (50\%) \\
\hline Low & $25(10 \%)$ & $25(26 \%)$ & - & $25(10 \%)$ & $25(26 \%)$ & - \\
\hline
\end{tabular}



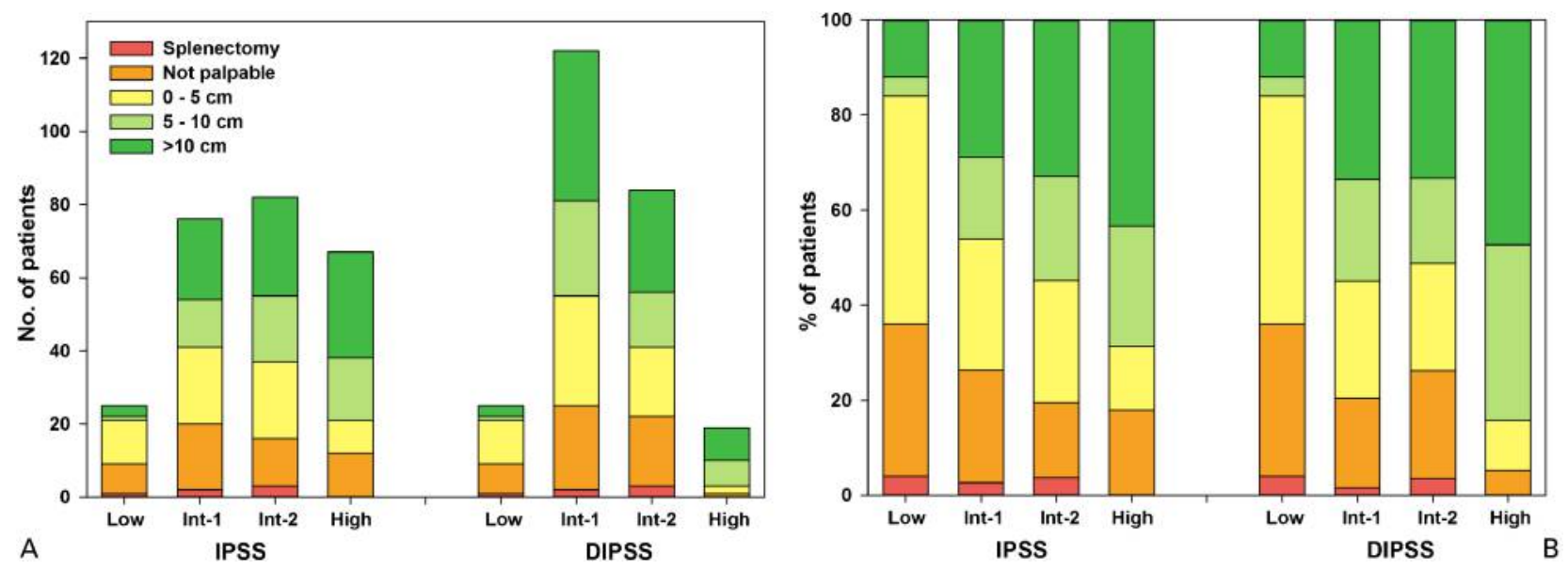

Figure 1 Distribution of patients according to IPSS or DIPSS risk categories and spleen size: (A) number of patients; (B) percentages.

The majority of patients had a myeloblast count $<1 \%(165 / 250 ; 66 \%)$. Of these, $73(44 \%)$ had a spleen size $\geq 5 \mathrm{~cm}$ below the costal margin and $52(32 \%)$ suffered from constitutional symptoms. Among patients with a myeloblast count $\geq 1 \% \quad(85 / 250$; $34 \%$ ), a high proportion $(57 / 85 ; 67 \%$ ) had a spleen size $\geq 5 \mathrm{~cm}$ below the costal margin and $34(40 \%)$ suffered from constitutional symptoms.

\section{Platelet counts and splenectomy/spleen irradiation in $\mathrm{MF}$}

Overall, six (2\%) patients (none High risk) had undergone a splenectomy. Of these, four patients had a platelet count $\geq 200000 / \mu 1$, one patient had a platelet count between 75000 and $100000 / \mu 1$, and one patient had a platelet count $<50000 / \mu$ l.

Overall, $13(5 \%)$ patients had undergone radiotherapy for splenomegaly. Of these, five patients had a platelet count $\geq 200000 / \mu 1$, three patients had a platelet count between 100000 and $200000 / \mu 1$, three patients had a platelet count between 50000 and $75000 / \mu 1$, and two patients had a platelet count $<50000 / \mu 1$.

\section{Discussion}

Here we have presented the results of a recently conducted survey designed to collect quantitative data to describe prevalence and study-specific disease parameters (diagnosis, risk categories, spleen size, cell count, myeloblast count) in Belgian MF patients in 2011.

We aimed to capture the majority of MF patients in Belgium by targeting 18 major hematology centers in Belgium. There is likely to be a bias for patients in the High and Intermediate risk categories as low-risk patients, with fewer symptoms, may not have been transferred to these centers. We estimate that the 250 patients captured here represent about $60 \%$ of the total population of MF patients in Belgium in 2011, considering a PMF prevalence ${ }^{37}$ of 2.7 per 100000 (population in 2011: 10.95 million) ${ }^{38}$ and accounting for the additional patients with secondary MF (34\% of the total MF population, according to the present survey). The majority of patients were over 65 years old, with a slightly higher proportion of men, as expected. ${ }^{5,7-9}$

The various symptoms and characteristics of MF contribute to a diminished quality of life for MF patients. In particular, splenomegaly, reported for over three quarters of the patients here, can be associated with pain, early satiety, bloating and potentially portal hypertension and portal vein thrombosis. ${ }^{20}$

In order to be considered for transplantation, age and risk category are important selection factors; older patients are less likely to be considered for AHSCT due to the toxicity associated with the procedure. In our survey, 97 out of 250 (39\%) MF patients were $\leq 65$ years old. Of these, $26(27 \%)$ were Int-2 and $12(12 \%)$ were High risk IPSS. Thus, only $38(15.2 \%)$ of all patients captured in this survey would be considered transplant candidates based on both age and risk category. It should be noted however that age above 65 is not a strict exclusion criterion for AHSCT, as each patient should be

Table 2 Platelet count distribution overall and per age class

\begin{tabular}{lccc}
\hline Platelet count $(\boldsymbol{\mu l})$ & Overall $\boldsymbol{N = 2 5 0}$ & $\mathbf{6 6 5}$ years $\mathbf{N = 9 7}$ & $>\mathbf{6 5}$ years $\mathbf{N = 1 5 3}$ \\
\hline$<50000$ & $28(11 \%)$ & $11(11 \%)$ & $17(11 \%)$ \\
$\geq 50000-<75000$ & $14(6 \%)$ & $3(3 \%)$ & $11(7 \%)$ \\
$\geq 75000-<100000$ & $7(3 \%)$ & $3(3 \%)$ & $4(3 \%)$ \\
$\geq 100000-<200000$ & $58(23 \%)$ & $20(21 \%)$ & $38(25 \%)$ \\
$\geq 200000$ & $143(57 \%)$ & $60(62 \%)$ & $83(54 \%)$ \\
\hline
\end{tabular}




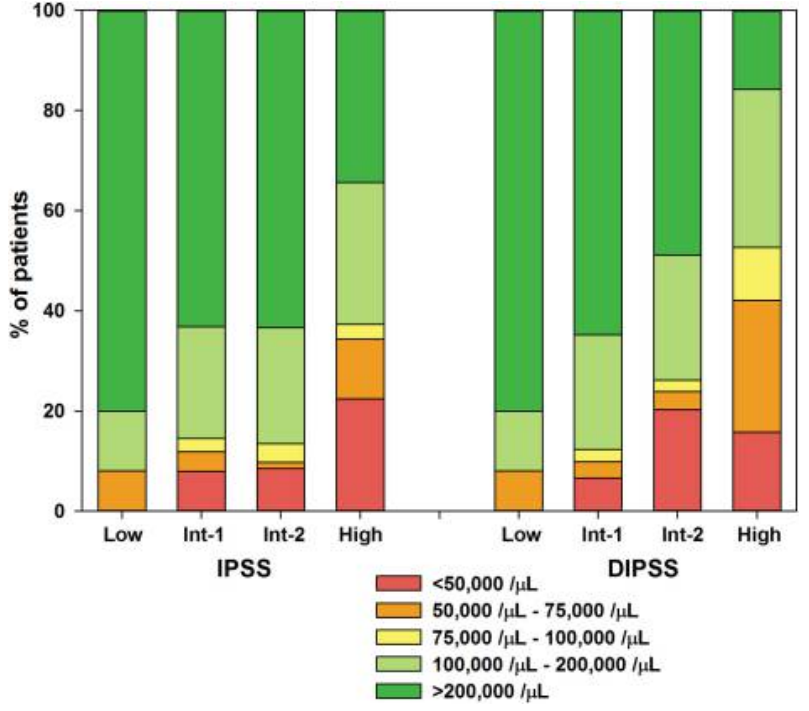

Figure 2 Distribution of patients (\%) according to IPSS or DIPSS risk categories and platelet count.

assessed on an individual base and age is not the only parameter to take into account. Thrombocytopenia is often present in MF patients and it has been added as a negative prognostic factor in the DIPSS Plus scoring system. ${ }^{12}$ In our survey, severe thrombocytopenia was not common. A total of $222(89 \%)$ of the patients had platelet counts $\geq 50000 / \mu 1$. Patients with very low platelet count $(<50000 / \mu$; approximately $11 \%$ of patients captured here) are usually not eligible to participate in clinical trials with JAK inhibitors. Thrombocytopenia is a common side effect of JAK inhibitors, ${ }^{31}$ and spontaneous bleeding could have fatal consequences for patients with very low platelets count. However, pacritinib (selective inhibitor for JAK2 and FLT3) was shown to alleviate MF-associated splenomegaly and constitutional symptoms in a Phase II clinical study, where seven out of 34 patients had platelet counts $<50000 / \mu 1 .{ }^{39}$ Different JAK inhibitors under clinical development are selective for different kinases. It remains unclear how the efficacy and side-effects of the JAK inhibitors

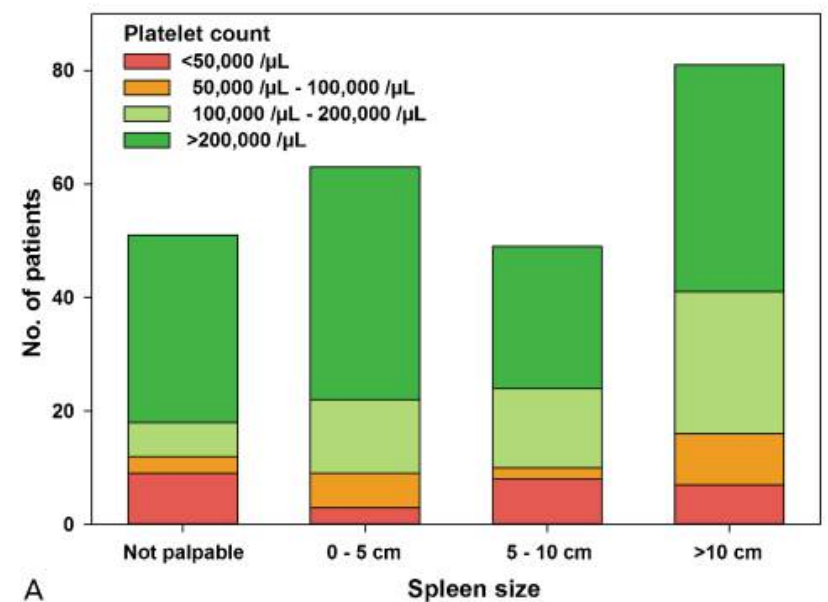

can be attributed to the inhibition of individual JAK family members, but it could be envisaged that MF patients may benefit from future rational drug combinations that target multiple signaling pathways. ${ }^{25,40}$

Ruxolitinib has been tested on Int-2 and High risk MF patients with platelet counts above $100000 / \mu 1$ and a spleen size over $5 \mathrm{~cm}$ in Phase III clinical trials. ${ }^{33,34}$ Data available to date suggest that ruxolitinib may improve survival versus placebo or best available therapy. ${ }^{41-43}$ The main drug sideeffects were thrombocytopenia, anemia and diarrhea. Due to the thrombocytopenic effect, ruxolitinib is not routinely indicated for patients with less than 100000 platelets $/ \mu 1$. However, ruxolitinib is currently being tested in Phase Ib/II clinical trials in thrombocytopenic MF patients (platelet counts of 50000 $100000 / \mu 1$ ) with positive results (reduction in splenomegaly and constitutional symptoms). ${ }^{44}$

In our survey, out of the total population with spleen size $\geq 5 \mathrm{~cm}$ under the costal margin and a platelet count above $50000 / \mu 1$, almost all patients (97\%) were Intermediate to High risk (IPSS and DIPSS). Three quarters IPSS and half DIPSS patients were Int-2 and High risk, respectively. While about one-third of these higher risk patients would be considered eligible for transplantation based on age, the remaining high risk patients could thus potentially benefit from treatment with hydroxyurea or JAK inhibitors. ${ }^{25-27}$ If we applied the inclusion criteria for the Comfort trials ${ }^{33,34}$ to the MF patient population included in the current study, 72/ $250(29 \%)$ patients would qualify (Int-2 and High risk categories [IPSS], spleen size $\geq 5 \mathrm{~cm}$ below the costal margin and a platelet count $\geq 100000 / \mu 1$ ). If we expanded this selection to include the Int-1 risk category (IPSS) and all patients Intermediate to High risk (IPSS) with a platelet count $\geq 50000 / \mu 1$, the proportion of MF patients captured by this survey who could potentially benefit from treatments with JAK inhibitors would be as high as $44 \%(111 / 250)$.

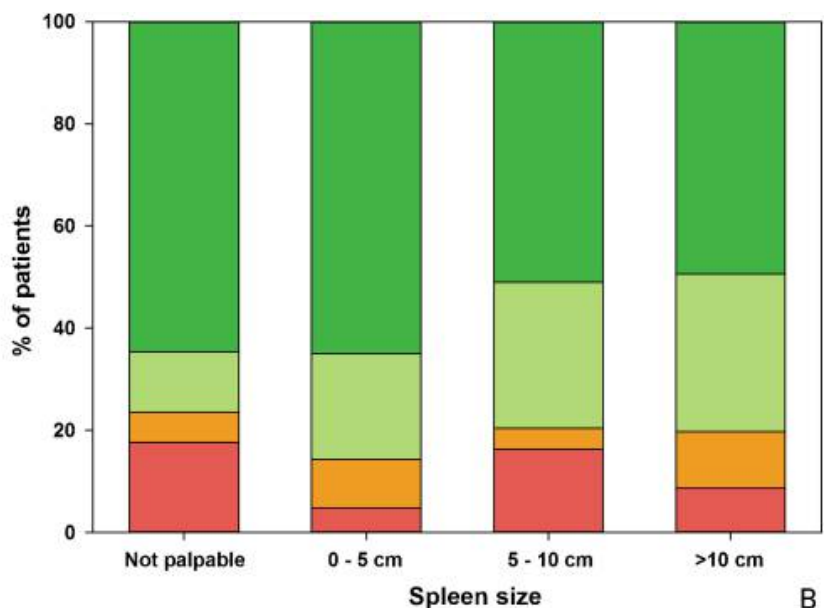

Figure 3 Distribution of patients according to spleen size and platelet count: (A) number of patients; (B) percentages. 

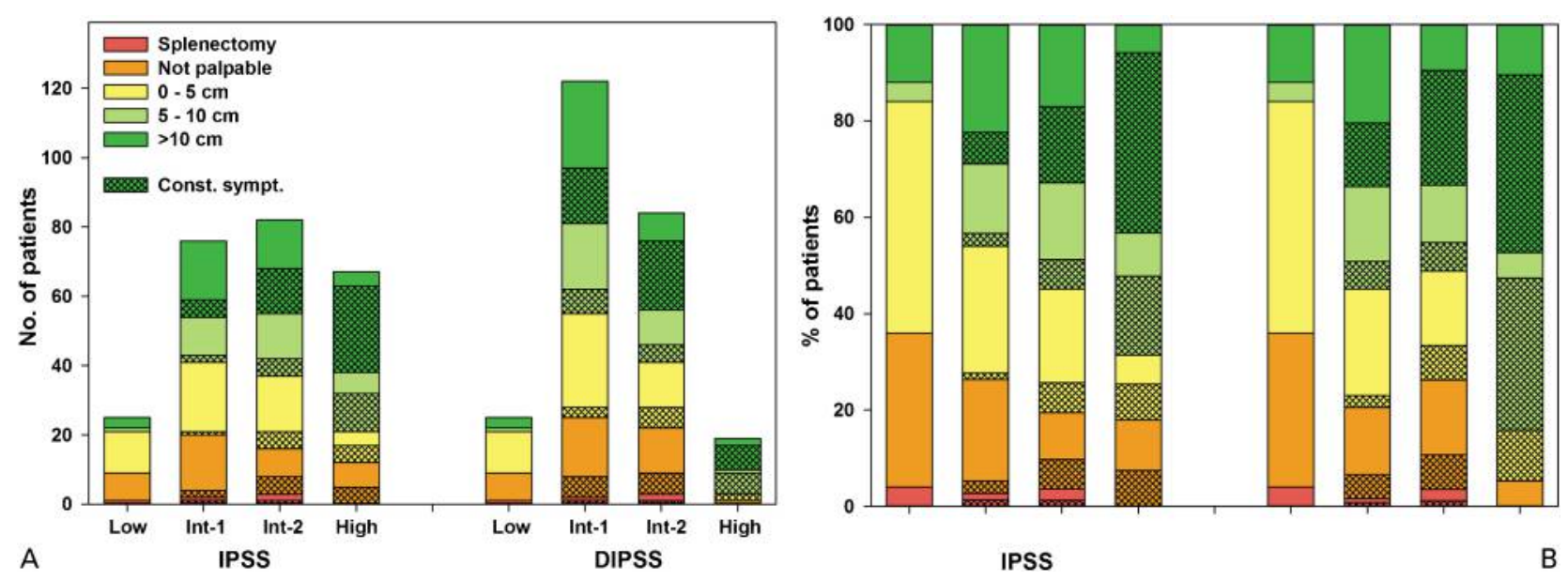

Figure 4 Distribution of patients according to IPSS or DIPSS risk categories, spleen size and presence of constitutional symptoms: (A) number of patients; (B) percentages.

The management of anemia, a major symptom of MF and a side-effect of some of the tested JAK inhibitors, can be a challenging aspect of treating patients with MF. ${ }^{33,34,45}$ MF-associated anemia is currently treated with ESAs, prednisone, danazol, thalidomide or lenalidomide. ${ }^{31}$ Pomalidomide, a derivative of thalidomide, was shown to be active in the treatment of anemia in Phase I/II trials, ${ }^{46}$ but in a recently conducted Phase III trial comparing low dose pomalidomide versus placebo in RBC-dependent MF patients, the primary endpoint, RBC-transfusion independence, has not been reached. ${ }^{47}$ Clinical trials are currently underway to test the possible benefits of combining ruxolitinib with anti-anemia drugs (thalidomide, lenalidomide, danazol, or ESAs). ${ }^{48}$ A limitation of the current study is the lack of information on anemia and transfusion-dependency, which lowers our understanding of the potential impact of anemia in the MF patients captured in this survey. Although hemoglobin concentration $(<10 \mathrm{~g} / \mathrm{dl})$ was used as a predictive risk factor in assessing IPSS and DIPSS risk groups, the pre-defined questions of this survey did not target the distribution of patients according to hemoglobin concentration or transfusion-dependency.

In conclusion, the results of this survey provide important insight into the characteristics of the Belgian MF population, according to specific disease parameters. They also suggest that a large proportion of these patients, particularly in the Intermediate to High risk categories, could benefit from treatment with investigational drugs under development. These new treatments, although they offer promise in the improvement in quality of life of certain MF patients, still do not offer a cure and may not yet be appropriate for all patients.

\section{Acknowledgements}

The authors would like to thank all investigators who took part in the survey. The authors also thank Vasile
Coman and Juliette Gray (XPE Pharma and Science) for medical writing assistance.

\section{References}

1 Vardiman JW, Thiele J, Arber DA, Brunning RD, Borowitz MJ, Porwit A, et al. The 2008 revision of the World Health Organization (WHO) classification of myeloid neoplasms and acute leukemia: rationale and important changes. Blood. 2009;114(5):937-51.

2 Mesa RA, Niblack J, Wadleigh M, Verstovsek S, Camoriano J, Barnes S, et al. The burden of fatigue and quality of life in myeloproliferative disorders (MPDs): an international Internetbased survey of 1179 MPD patients. Cancer. 2007;109(1):68-76.

3 Tefferi A. Myelofibrosis with myeloid metaplasia. N Engl J Med. 2000;342(17):1255-65.

4 Cervantes F, Passamonti F, Barosi G. Life expectancy and prognostic factors in the classic BCR/ABL-negative myeloproliferative disorders. Leukemia. 2008;22(5):905-14.

5 Maynadie M, Girodon F, Manivet-Janoray I, Mounier M, Mugneret F, Bailly F, et al. Twenty-five years of epidemiological recording on myeloid malignancies: data from the specialized registry of hematologic malignancies of Cote d'Or (Burgundy, France). Haematologica. 2011;96(1):55-61.

6 Cervantes F, Dupriez B, Pereira A, Passamonti F, Reilly JT, Morra E, et al. New prognostic scoring system for primary myelofibrosis based on a study of the International Working Group for Myelofibrosis Research and Treatment. Blood. 2009;113(13):2895-901.

7 Johansson P, Kutti J, Andreasson B, Safai-Kutti S, Vilen L, Wedel H, et al. Trends in the incidence of chronic Philadelphia chromosome negative (Ph-) myeloproliferative disorders in the city of Goteborg, Sweden, during 1983-99. J Intern Med. 2004;256(2):161-5.

8 Osca-Gelis G, Puig-Vives M, Saez M, Gallardo D, Lloveras N, Marcos-Gragera R. Population-based incidence of myeloid malignancies: fifteen years of epidemiological data in the province of Girona, Spain. Haematologica. 2013;98(8):e95-7.

9 Phekoo KJ, Richards MA, Moller H, Schey SA. The incidence and outcome of myeloid malignancies in 2,112 adult patients in southeast England. Haematologica. 2006;91(10):1400-4.

10 Visser O, Trama A, Maynadie M, Stiller C, Marcos-Gragera R, De Angelis $\mathrm{R}$, et al. Incidence, survival and prevalence of myeloid malignancies in Europe. Eur $\mathrm{J}$ Cancer. 2012;48(17):3257-66.

11 Passamonti F, Cervantes F, Vannucchi AM, Morra E, Rumi E, Pereira A, et al. A dynamic prognostic model to predict survival in primary myelofibrosis: a study by the IWG-MRT (International Working Group for Myeloproliferative Neoplasms Research and Treatment). Blood. 2010;115(9):1703-8.

12 Gangat N, Caramazza D, Vaidya R, George G, Begna K, Schwager S, et al. DIPSS plus: a refined Dynamic International Prognostic Scoring System for primary myelofibrosis that incorporates prognostic information from karyotype, platelet count, and transfusion status. J Clin Oncol. 2011;29(4):392-7. 
13 Deeg HJ, Gooley TA, Flowers ME, Sale GE, Slattery JT, Anasetti C, et al. Allogeneic hematopoietic stem cell transplantation for myelofibrosis. Blood. 2003;102(12):3912-8.

14 Ditschkowski M, Beelen DW, Trenschel R, Koldehoff M, Elmaagacli AH. Outcome of allogeneic stem cell transplantation in patients with myelofibrosis. Bone Marrow Transplant. 2004;34(9):807-13.

15 Kroger N, Holler E, Kobbe G, Bornhauser M, Schwerdtfeger $\mathrm{R}$, Baurmann $\mathrm{H}$, et al. Allogeneic stem cell transplantation after reduced-intensity conditioning in patients with myelofibrosis: a prospective, multicenter study of the Chronic Leukemia Working Party of the European Group for Blood and Marrow Transplantation. Blood. 2009;114(26):5264-70.

16 Ballen KK, Shrestha S, Sobocinski KA, Zhang MJ, Bashey A, Bolwell BJ, et al. Outcome of transplantation for myelofibrosis. Biol Blood Marrow Transplant. 2010;16(3):358-67.

17 Abdel-Wahab OI, Levine RL. Primary myelofibrosis: update on definition, pathogenesis, and treatment. Annu Rev Med. 2009; $60: 233-45$.

18 Tefferi A. How I treat myelofibrosis. Blood. 2011;117(13):3494 504.

19 Mesa RA, Nagorney DS, Schwager S, Allred J, Tefferi A. Palliative goals, patient selection, and perioperative platelet management: outcomes and lessons from 3 decades of splenectomy for myelofibrosis with myeloid metaplasia at the Mayo Clinic. Cancer. 2006;107(2):361-70.

20 Mesa RA. How I treat symptomatic splenomegaly in patients with myelofibrosis. Blood. 2009;113(22):5394-400.

21 Baxter EJ, Scott LM, Campbell PJ, East C, Fourouclas N, et al. Acquired mutation of the tyrosine kinase JAK2 in human myeloproliferative disorders. Lancet. 2005;365(9464):1054-61.

22 James C, Ugo V, Le Couedic JP, Staerk J, Delhommeau F, Lacout $\mathrm{C}$, et al. A unique clonal JAK2 mutation leading to constitutive signalling causes polycythaemia vera. Nature. 2005;434(7037): $1144-8$.

23 Kralovics R, Passamonti F, Buser AS, Teo SS, Tiedt R, Passweg $\mathrm{JR}$, et al. A gain-of-function mutation of JAK2 in myeloproliferative disorders. N Engl J Med. 2005;352(17):1779-90.

24 Levine RL, Wadleigh M, Cools J, Ebert BL, Wernig G, Huntly $\mathrm{BJ}$, et al. Activating mutation in the tyrosine kinase JAK2 in polycythemia vera, essential thrombocythemia, and myeloid metaplasia with myelofibrosis. Cancer Cell. 2005;7(4):387-97.

25 Tam CS, Verstovsek S. Investigational Janus kinase inhibitors Expert Opin Investig Drugs. 2013;22(6):687-99.

26 Sonbol MB, Firwana B, Zarzour A, Morad M, Rana V, Tiu RV. Comprehensive review of JAK inhibitors in myeloproliferative neoplasms. Ther Adv Hematol. 2013;4(1):15-35

27 Komrokji R, Verstovsek S. Assessing efficacy in myelofibrosis treatment: a focus on JAK inhibition. Expert Rev Hematol. 2012;5(6):631-41.

28 Barbui T, Barosi G, Birgegard G, Cervantes F, Finazzi G, Griesshammer M, et al. Philadelphia-negative classical myeloproliferative neoplasms: critical concepts and management recommendations from European LeukemiaNet. J Clin Oncol. 2011;29(6):761-70.

29 Reilly JT, McMullin MF, Beer PA, Butt N, Conneally E, Duncombe A, et al. Writing group: British Committee for Standards in H. Guideline for the diagnosis and management of myelofibrosis. Br J Haematol. 2012;158(4):453-71.

30 Barosi G, Lupo L, Rosti V. Management of myeloproliferative neoplasms: from academic guidelines to clinical practice. Curr Hematol Malig Rep. 2012;7(1):50-6.

31 Tefferi A. Primary myelofibrosis: 2013 update on diagnosis, risk-stratification, and management. Am J Hematol. 2013;88(2): $141-50$.
32 Mascarenhas J, Hoffman R. A comprehensive review and analysis of the effect of ruxolitinib therapy on the survival of patients with myelofibrosis. Blood. 2013;121(24):4832-7.

33 Harrison C, Kiladjian JJ, Al-Ali HK, Gisslinger H, Waltzman $\mathrm{R}$, Stalbovskaya $\mathrm{V}$, et al. JAK inhibition with ruxolitinib versus best available therapy for myelofibrosis. $\mathrm{N}$ Engl J Med. 2012;366(9):787-98.

34 Verstovsek S, Mesa RA, Gotlib J, Levy RS, Gupta V, DiPersio $\mathrm{JF}$, et al. A double-blind, placebo-controlled trial of ruxolitinib for myelofibrosis. N Engl J Med. 2012:366(9):799-807.

35 Mascarenhas J, Hoffman R. Ruxolitinib: the first FDA approved therapy for the treatment of myelofibrosis. Clin Cancer Res. 2012;18(11):3008-14.

36 Pardanani A, Laborde RR, Lasho TL, Finke C, Begna K, Al-Kali A, et al. Safety and efficacy of CYT387, a JAK1 and JAK2 inhibitor, in myelofibrosis. Leukemia. 2013;27(6):1322-7.

37 Orphanet Report Series. Prevalence of rare diseases: Bibliographic data 2011. Available from: http://www.orpha.net (accessed 17 March 2014).

38 Statistical Overview of Belgium. Key figures 2012. Available from: http://statbel.fgov.be (accessed 17 March 2014).

39 Komrokji RS, Wadleigh M, Seymour JF, Roberts AW, Bik L, Zhu HJ, et al. Results of a Phase 2 Study of Pacritinib (SB1518), a Novel Oral JAK2 Inhibitor, in Patients with Primary, Post-Polycythemia Vera, and Post-Essential Thrombocythemia Myelofibrosis. Paper presented at the ASH Annl Meet; 2011 Dec 10-13; San Diego, CA, USA.

40 Santos FP, Verstovsek S. What is next beyond janus kinase 2 inhibitors for primary myelofibrosis? Curr Opin Hematol. 2013;20(2):123-9.

41 Verstovsek S, Kantarjian HM, Estrov Z, Cortes JE, Thomas DA, Kadia T, et al. Long-term outcomes of 107 patients with myelofibrosis receiving JAK1/JAK2 inhibitor ruxolitinib: survival advantage in comparison to matched historical controls. Blood. 2012;120(6):1202-9.

42 Verstovsek S, Mesa RA, Gotlib J, Levy RS, Gupta V, Dipersio $\mathrm{JF}$, et al. Efficacy, safety and survival with ruxolitinib in patients with myelofibrosis: results of a median 2-year followup of COMFORT-I. Haematologica. 2013;98(12):1865-71.

43 Cervantes F, Vannucchi AM, Kiladjian JJ, Al-Ali HK, Sirulnik A, Stalbovskaya V, et al. Three-year efficacy, safety, and survival findings from COMFORT-II, a phase 3 study comparing ruxolitinib with best available therapy for myelofibrosis. Blood. 2013;122(25):4047-53.

44 Talpaz M, Paquette R, Afrin L, Hamburg SI, Prchal JT, Jamieson $\mathrm{K}$, et al. Interim analysis of safety and efficacy of ruxolitinib in patients with myelofibrosis and low platelet counts. J Hematol Oncol. 2013;6(1):81.

45 Pardanani A, Gotlib JR, Jamieson C, Cortes JE, Talpaz M, Stone RM, et al. Safety and efficacy of TG101348, a selective JAK2 inhibitor, in myelofibrosis. J Clin Oncol. 2011;29(7):789_ 796.

46 Tefferi A, Verstovsek S, Barosi G, Passamonti F, Roboz GJ, Gisslinger $\mathrm{H}$, et al. Pomalidomide is active in the treatment of anemia associated with myelofibrosis. J Clin Oncol. 2009;27(27): 4563-4569.

47 Tefferi A, Passamonti F, Barbui T, Barosi G, Begna K, Cazzola M, et al. Phase 3 Study Of Pomalidomide In Myeloproliferative Neoplasm (MPN)-Associated Myelofibrosis With RBCTransfusion-Dependence. Paper presented at the ASH Annl Meet; 2013 Dec 7-10; New Orleans, LA, USA.

48 Keohane C, Radia DH, Harrison CN. Treatment and management of myelofibrosis in the era of JAK inhibitors. Biologics. 2013;7:189-98. 